November 2016

\title{
Whither Megaleaking? Questions in the Wake of the Panama Papers
}

Lisa Lynch

Drew University

David S. Levine

Elon University School of Law

Follow this and additional works at: https://scholarworks.sjsu.edu/secrecyandsociety

Part of the History Commons, Law Commons, Political Science Commons, and the Public Affairs, Public Policy and Public Administration Commons

\section{Recommended Citation}

Lynch, Lisa and David S. Levine. 2016. "Whither Megaleaking? Questions in the Wake of the Panama Papers." Secrecy and Society 1(1). https://doi.org/10.31979/

2377-6188.2016.010107 https://scholarworks.sjsu.edu/secrecyandsociety/vol1/iss1/7

This Article is brought to you for free and open access by the School of Information at SJSU ScholarWorks. It has been accepted for inclusion in Secrecy and Society by an authorized administrator of SJSU ScholarWorks. For more information, please contact scholarworks@sjsu.edu.

\section{(c) (1)}

This work is licensed under a Creative Commons Attribution 4.0 License. 


\section{Whither Megaleaking? Questions in the Wake of the Panama Papers}

\section{Keywords}

International Coalition of Investigative Journalists, leaks, Panama Papers, security

classification, Edward Snowden, whistleblowing 


\section{Whither Megaleaking? Questions in the Wake of the Panama Papers}

\section{Lisa Lynch and David S. Levine}

In early April of 2016, the International Coalition of Investigative Journalists released a series of investigations drawn from the largest collection of leaked documents to date: 11.5 million files covering 40 years' worth of transactions from over 14,000 law firms, banks and incorporation agencies that had hired the Panamanian law firm Mossack Fonseca to assist in creating offshore companies for purposes of tax avoidance. The investigation implicated at least 140 political figures, including the Prime Minister of Iceland (who subsequently resigned), a close friend of Vladmir Putin, member of China's highranking families, and (ironically) the head of the Chilean branch of Transparency International. Though the documents were not released en masse, a total of 400 journalists from 76 countries pored through them using a purpose-built database and a customized social network that allowed them to communicate their findings securely. During the course of the investigation, which took over a year, all the journalists and their media outlets respected an embargo agreement that kept their findings secret until a pre-arranged collective deadline. 
While the contents of Mossack Fonseca leak has been revelatory, the fact of the leak itself and the breadth of the subsequent investigation was not as astonishing as it might have seemed only a few years ago. "Megaleaks" or unauthorized releases of an extraordinary amount of data obtained and circulated using advances in digital technologies, are by now familiar terrain for both journalists and their audiences (Greenberg 2012). Other recent examples include the Wikileaks War Logs and Cablegate release, the Edward Snowden files, and the ICIJ's own "LuxLeaks" and "OffshoreLeaks" releases. In each case, these megaleaks have been motivated, at least professedly, by concerns about malfeasance and hopes for political and financial reform. And in each case, these leaks have produced economic and political responses on a global scale.

Without questioning the motives of the leakers - or the merits of such reforms - we want to set out some research and policy questions to be considered as the megaleaks phenomenon continues to evolve. We intend to address some or all of these questions in upcoming scholarship, but encourage other researchers to incorporate these questions and issues into their own projects.

\section{Question One: Is a financial megaleak a new form of financial transparency, or is it part of a general trend towards openness}


Lynch and Levine: Whither Megaleaking?

\section{in financial practice and regulation? Does that distinction matter?}

Over the past several years in the wake of "Too Big to Fail," and especially given the success of both Bernie Sanders and Donald Trump in appeals to populist challenges to the American financial system, there has been an increased focus on "transparency" as a check against the excesses of unregulated industry. The result has been measured efforts at forcing openness and sharing within an industry unused to such pressure. To be sure, sharing information is not an alien concept in the financial world. But while sharing information with regulators and the public in Securities and Exchange Commission filings or in prospectuses sent to investors constitutes one form of openness, such openness has been targeted at specific regulatory goals (i.e., preventing fraud, deterring insider trading). The new megaleak is a much bolder and less targeted action, with one seeming purpose: openness for the sake of openness and generalized accountability. It gives the public the benefit of a trove of information, but the search and analysis functions fall to the public. As that trove needs to be understood, serendipity and knowledge of financial intricacies play a critical role in drawing lessons from that which is leaked.

Thus, should this be viewed as another form of regulation, or 
dismissed as the anarchist actions of a lawless society? Is this the proverbial "document dump," so common and ridiculed in modern civil litigation? Or is this a much more purposeful action, in which legitimate regulatory goals like checks against abuse and maintenance of commercial ethics are advanced? Is it both?

\section{Question Two: Are whistleblowing and leaking effective mechanisms for shedding light on legal, as opposed to wasteful, fraudulent or abusive, activities? Is this a form of accountability?}

Transparency and accountability have become largely synonymous with preventing the proverbial "waste, fraud and abuse." Indeed, "waste, fraud and abuse" has become a generalized term used to answer a range of regulatory questions for decades, from "why do we have a massive national debt" to "why did [politician] vote that way?" The Panama Papers points in a different direction, focusing on transparency and openness so as to reveal what is legal under existing law and regulation. Presumably, law and regulation are reflections of the will of the people, at least in a democracy. If that's theoretically true, than we should not need access to information as a form of democratic legitimacy. Yet, the Panama Papers reveal much that, while legal, is not well understood or even known, arguably necessitating the 
leak (even as the density of the material militates against its necessity in public hands). If that's the case, then should the Panama Papers be viewed as part of a new form of democratic accountability?

\section{Question Three: Can institutions create architectural and cultural barriers to leaking and whistleblowing that simultaneously serve the interests of the public and the institution?}

In the wake of the Edward Snowden leaks, there were some who criticized Snowden for failing to use internal NSA channels to share his concerns (Schanzer 2014). In that narrative, Snowden's objective was not to altruistically share information with the public about issues ignored within the NSA, but rather to damage national security in the name of an egomania, self-interest and outright disloyalty (to be sure, his safe harbor in Russia has not helped dispel those concerns). Thus, a core leaking and whistleblowing question is one of administration: can institutions maintain information which should be kept secret - a massive question worthy of increased study in its own right - that simultaneously serve an administrative entity's interest in discretion and deliberation while also allowing the public assurance and knowledge that the institution is serving the public's interest?

\section{Question Four: Should we be concerned about the potential}


Secrecy and Society, Vol. 1, No. 1 [2016], Art. 7

\section{geopolitical destabilization caused by successive rounds of megaleaks?}

Since the early 1990s, media observers have debated whether there is a "CNN Effect," meaning the deterioration in the quality of political deliberation and planning due to the constant pressures of a 24-hour news cycle. We should now wonder instead about the nature of the "megaleaks effect," and whether it is entirely salutary. The political fallout from recent "megaleaks" has been impressive in both reach and significance, with disclosures from Wikileaks, Edward Snowden and the anonymous leaker of the Pentagon Papers prompting everything from policy reform to regime change. But this process of catalyzing sometimes extraordinary acts of political or policy change in this instance, we can cite both the resignation of the Prime Minister of Iceland and the decision of Panama to finally adhere to OECD rules surrounding financial transparency - is inherently destabilizing. Without contesting the need for the reforms prompted by megaleaks investigations, we can nonetheless question whether such simultaneous high-impact disclosures might cause serious geopolitical issues in the future.

\section{Question Five: Given the growth and increasing resonance of} foundation-funded international journalism collaborations, how 


\section{do we set standards so that leak investigations of this scale are not motivated by financial or political goals of funders (let alone leakers)?}

Over the past decade, the downsizing of newsrooms and news resources in the US and elsewhere - combined with the rising prominence of crowdsourced data journalism projects - has helped to fuel the rise of national and international journalism collaboratives that exist alongside legacy media outlets and are funded primarily by foundations or wealthy donors. In countries where the press has traditionally relied either on advertising or government subsidies, such media outlets are seen as susceptible to bias, especially when they engage in politically sensitive reporting. In the case of the Panama Papers, the ICIJ has received substantial funding from George Soros' Open Society Institute, a circumstance that has led to some conspiracy-level speculation as to the motives of the investigation. Bloggers on sites including Brietbart and Infowars have emphasized connections between Soros and the ICIJ, claiming that claimed Soros is using the ICIJ to go after Putin and his allies. As well, other bloggers have claimed that the ICIJ is a CIA front, pointing to the fact that few US shell corporations have been disclosed by reporters working on the Papers.

While these accusations are marginal responses to the Panama 
Papers phenomenon, they do highlight the particular challenges that foundation-funded media outlets will face as they increasingly shoulder the burden of investigative work; their financial model means that they are tied to the very segment of society whose financial dealings might be worthy targets of investigation. In the future, this might result in legitimate conflicts or interest or a crisis of support for foundationfunded media.

Question Six: Given the accelerating size and pace of the leaks themselves, can we expect the complex structure of multinational embargo agreements that guide such investigations to hold up in the future?

One of the ironies of all "megaleaks" journalism is that as exercises in transparency, they are dependent on complex secrecy agreements; namely, the embargoes that prevent media outlets from reporting on potentially explosive material during the entire process of investigation. These alliances are rendered unstable by the competitive nature of news reporting; for example, during the War Diary and Cablegate leaks orchestrated by Wikileaks, Al Jazeera chose to "scoop" the other outlets involved with early release of leaked material. By contrast, the Panama Papers was an exemplary instance of embargo cooperation, with approximately 400 journalists keeping 
their reporting processes and conclusions a secret, even when it was clear their investigations would have dramatic impact. But it is reasonable to expect that megaleaks will not be able to scale indefinitely, and to imagine a future investigation descending into chaos after one reporter reveals the existence of a megaleak either voluntarily or due to coercion.

\section{References}

Greenberg, Andy. This Machine Kills Secrets: Julian Assange, The Cypherpunks, and Their Fight to Empower Whistleblowers. New York: Penguin, 2012.

Schanzer, David. 2014. Prof. David Schanzer on Edward Snowden Show 216. Podcast audio. July 18. MP3. 57:22. Accessed November 17, 2016. http://www.hearsayculture.com/show-216prof-david-schanzer-on-edward-snowden-posted/

Lisa Lynch is Visiting Associate Professor at Drew University. Her work is situated at the intersection between culture, technology, and political change, focusing on topics including new media, information access, global internet governance issues, and human rights. Some of her more prominent research has focused on the growth of leaking platforms and their use by journalists. She has been a visiting fellow at Princeton's Center for Information Technology Policy and an affiliate at Data and Society.

David S. Levine is an Associate Professor of Law at Elon University School of Law and an Affiliate Scholar at the Center for Internet and Society at Stanford Law School (CIS). He is a 2015-2016 Visiting Research Collaborator at Princeton University's Center for Information Technology Policy (CITP). He is also the founder and host of Hearsay 
Culture on KZSU-FM (Stanford University), an information policy, intellectual property law and technology talk show for which he has recorded over 250 interviews since May 2006. His scholarship focuses on the operation of intellectual property law at the intersection of technology and public life, specifically information flows in the lawmaking and regulatory process and intellectual property law's impact on public and private secrecy, transparency and accountability. 